Check for updates

Cite this: RSC Adv., 2017, 7, 31100

\section{Electrochemical deposition of nickel graphene composite coatings: effect of deposition temperature on its surface morphology and corrosion resistance $\dagger$}

\author{
Abdul Jabbar, $\star^{\mathrm{a}}$ Ghulam Yasin, ${ }^{\mathrm{b}}$ Waheed Qamar Khan, ${ }^{\mathrm{c}}$ M. Yousaf Anwar, (DD *a \\ Rashid Mustafa Korai, ${ }^{\mathrm{b}}$ Muhammad Naeem Nizam ${ }^{\mathrm{b}}$ and Ghulam Muhyodin ${ }^{\mathrm{b}}$
}

\begin{abstract}
The present work describes the fabrication of $\mathrm{Ni}$-graphene composite coatings on carbon steel at different deposition temperatures $\left(15^{\circ} \mathrm{C}, 30^{\circ} \mathrm{C}, 45^{\circ} \mathrm{C}\right.$ and $60^{\circ} \mathrm{C}$, respectively) by an electrochemical codeposition method. The surface morphology, compositions, roughness and phase structures were examined by scanning electron microscopy (SEM), energy dispersive spectroscopy (EDS), atomic force microscopy (AFM) and X-ray diffractometer (XRD), respectively. The polarization test and electrochemical impedance spectroscopy (EIS) were used to study the electrochemical properties of composite coatings. The results showed that the $\mathrm{Ni}$-graphene composite coatings deposited at $45{ }^{\circ} \mathrm{C}$ exhibit coarser surface morphology with increased carbon content, refined grain sizes, high micro hardness and better corrosion resistance performance. At lower temperature relatively flat $\mathrm{Ni}$-graphene composite coatings were obtained and the same characteristics of the coatings were investigated at higher than the peak value of the bath temperature. Thickness increased with the increasing of deposition temperature. The linear changes in composition and surface morphology of the $\mathrm{Ni}$-graphene composite coatings were observed when the deposition temperature reached up to $45^{\circ} \mathrm{C}$.
\end{abstract}

Received 27th December 2016 Accepted 26th May 2017

DOI: $10.1039 / \mathrm{c} 6 \mathrm{ra} 28755 \mathrm{~g}$

rsc.li/rsc-advances electrodeposition methods; among all of them, the electrodeposition technique deserves more attention because it has been shown to be an economical method, involving simple setup and less production of waste. ${ }^{11-18}$

Composite coatings are prepared on the substrates for the purpose of protecting the materials from corrosion and improving the surface properties, and in composite electrodeposition techniques the micro/nano particles or fibers are induced into a metal matrix by the electrodeposition process. The composite coatings have the combined effect of the metal matrix and reinforcer, resulting in its special applications in industry. Many researchers have investigated the effects of co-deposition of $\mathrm{SiO}_{2}, \mathrm{Al}_{2} \mathrm{O}_{3}, \mathrm{TiO}_{2}, \mathrm{SiC}$ and CNT into metal matrix. ${ }^{19-25}$ The results showed that the composite coatings possess improved hardness, better wear and corrosion resistance than pure nickel coatings. More recently, the study has expanded to demonstrated the graphene based corrosion resistance composite coatings. ${ }^{26}$

Graphene has all properties of material required for anticorrosion coatings including being lightweight, impermeable, atomically thin, wear resistant, inert in nature and mechanically strong. Graphene based composite coatings are widely used for the purpose of anti-corrosion and surface properties due to enormous and unique properties of graphene. C. M. Praveen Kumar $^{27}$ prepared the Ni-graphene composite coatings on the carbon steel substrate for anti-corrosion applications. Results

\footnotetext{
${ }^{a}$ Department of Metallurgical \& Materials Engineering, University of Engineering and Technology, Lahore-54000, Punjab, Pakistan.E-mail: myanwar86@hotmail.com

${ }^{b}$ State Key Laboratory of Chemical Resource Engineering, Beijing University of Chemical Technology, Beijing 100029, P. R. China

${ }^{c}$ College of Materials Science and Engineering, Beijing University of Technology, Beijing, 100029, P. R. China

$\dagger$ Electronic supplementary information (ESI) available. See DOI: $10.1039 / \mathrm{c} 6 \mathrm{ra} 28755 \mathrm{~g}$

\$ Equal contribution.
} 
demonstrate that the micro hardness and corrosion resistance increased significantly.

H. Algul et al. ${ }^{28}$ reported that the addition of graphene into coatings results in enhanced micro hardness, wear resistance and improved tribological properties of composite coatings due to the superior mechanical strength and lubricating effect of graphene. Sn and graphene composite coatings were electrodeposited on mild steel, which increased the anti-corrosion behavior of composite coatings than pure Sn coatings. ${ }^{29}$ Chen et al. $^{30}$ demonstrated that the graphene can protect copper from oxidation, and they reported the good performance of graphene coatings as a passivation layer. They also observed the ability of graphene to prevent the diffusion. Graphene also inhibit the corrosion of iron in aggressive chloride environment. ${ }^{31}$ Graphene coating layer possess corrosion resistance in environment of salt water and also shows better corrosion protection at high temperature for long time as compared with bare metals exposed to salty environment and at higher temperature. ${ }^{32}$ Results showed that graphene based coatings increased corrosion resistance of different metals significantly; in addition, graphene exhibit high flexibility which is helpful for the curvature or the surface roughness of coated substrate to a large extent, flexibility is good for coatings applications as well as for flexible electronics. ${ }^{33,34}$ Thermodynamically, graphene is very stable because the stability arising from long-range dislocation of the $\pi$-electron cloud, making an extended $\mathrm{C}=\mathrm{C}$ bonds aromatic network across the entire basal plane. Thus, because of the unique physio-chemical properties of graphene, recently graphene based coatings on metal substrate for enhanced surface properties have become the hot topic for researchers. Kyle Jiang ${ }^{35}$ studied the co-deposition of Ni-graphene composite coatings on carbon steel by electrodeposition process, they reported that $\mathrm{Ni}$-graphene composite coatings increased the micro hardness and improved the corrosion resistance of steel than pure nickel coatings. Results demonstrated that the graphene based composite coatings increased the corrosion resistance of materials and also enhanced the tribological properties of substrate.

Although the recent advances in the field of nanomaterials have opened the new possibilities for the fabrications of new devices, but they also have raised some new issues. For example, a number of problems arise in dealing with the electrodeposition of metals for different properties. ${ }^{36,37}$ Extensive studies have been conducted for the investigation of effects of electrodeposition parameters including bath composition, $\mathrm{pH}$, deposition time, additive/surfactants, deposition current density and bath temperature on the properties of deposited films. ${ }^{38-43}$ Therefore, only if the various deposition parameters influence the mechanism of Ni-graphene composite coatings, then acceptable research would be developed. Deposition temperature is one of the main factors of electrodeposition process, because it directly influences the composition, structure, and properties of coatings. ${ }^{44}$ In the most cases the deposition rate of the coatings is also related to the deposition temperature, usually due to the rise of temperature the diffusion rate of metals from the electrolyte is accelerated. ${ }^{45}$ It was observed from the previous studies that the composition of the nickel-graphene composite coatings is dependent on the deposition temperature, if the remaining bath parameters were fixed. However, the purpose of this study was to optimize the electrodeposition technique. Actually, the effects of temperature variation on the changes of composition, structure and properties of Ni-graphene composite coatings are not studied significantly.

In the present research work, the effects of deposition temperature on the characteristics and properties of electrodeposited $\mathrm{Ni}$-graphene composite coatings were investigated in details. Scanning electron microscope (SEM), energy dispersive spectroscopy (EDS) and X-ray diffractometer (XRD) were used to characterize the surface morphology, composition and structure of composite coatings respectively. Vickers's micro hardness testing machine and electrochemical workstation were applied to analyze the possible changes in micro hardness and electrochemical properties of composite coatings influenced by variation of deposition temperatures.

\section{Experimental}

Natural graphite with 325 mesh was purchased from Qingdao Ruisheng Graphite Company Ltd. All the others chemicals of analytical grade were purchased from Beijing Chemical Works. The substrate material was Q235 carbon steel with the chemical composition shown in Table 1.

\subsection{Synthesis of graphene}

The graphene oxide was synthesized by improved Hummer's method, chemical exfoliation of graphite flakes that is general approach to prepare graphene oxide ${ }^{46}$ briefly $1 \mathrm{~g}$ graphite flakes and $6 \mathrm{~g} \mathrm{KMnO}_{4}$ were added into the mixture of concentrated acids of $180 \mathrm{ml} \mathrm{H}_{2} \mathrm{SO}_{4}$ and $20 \mathrm{ml} \mathrm{H}_{3} \mathrm{PO}_{4}$, which produced a slight exothermic reaction at 35 to $40{ }^{\circ} \mathrm{C}$. The reaction was shifted to $50^{\circ} \mathrm{C}$ and stirred for 12 hours. Then the reaction was kept for cooling at room temperature and $400 \mathrm{ml}$ ice water along with the $30 \% \mathrm{H}_{2} \mathrm{O}_{2}(3 \mathrm{ml})$ were added. The obtained mixtures were saved for 24 hours. The supernatants were decanted away from the suspension by centrifugation (8000 rpm for 5 hour), after repeatedly washing, the obtained materials was shifted into the glass plate and dried it for 24 hours at $60^{\circ} \mathrm{C}$ in vacuum, solid product GO was obtained. Further, graphene oxide was reduced into graphene by chemically reduction method through using hydrazine hydrate as a reducing agent. ${ }^{47}$

\subsection{Electrodeposition process}

The electrodeposition process was performed to prepare the $\mathrm{Ni}-$ graphene composite coatings. The samples of carbon steel grade Q235 with size of $10 \times 20 \times 2 \mathrm{~mm}$ was used as substrate (cathode) for the composite coatings. The chemical composition of Q235 carbon steel is given in the Table 1 .

Table 1 Chemical composition (wt\%) of carbon steel grade (Q235)

\begin{tabular}{lllllllll}
\hline Elements & $\mathrm{C}$ & $\mathrm{Si}$ & $\mathrm{Mn}$ & $\mathrm{S}$ & $\mathrm{P}$ & $\mathrm{O}$ & $\mathrm{N}$ & $\mathrm{Fe}$ \\
$\mathrm{wt} \%$ & $0.14-0.20$ & 0.30 & $0.30-0.70$ & $<0.04$ & $<0.04$ & 0.01 & 0.004 & bal.
\end{tabular}


Table 2 Chemical composition of bath solution for electrodeposition process

\begin{tabular}{ll}
\hline Chemicals & $\left(\mathrm{g} \mathrm{L}^{-1}\right)$ \\
\hline $\mathrm{NiSO}_{4} \cdot 6 \mathrm{H}_{2} \mathrm{O}$ & $95-110$ \\
$\mathrm{NiCl}_{2} \cdot 6 \mathrm{H}_{2} \mathrm{O}$ & $15-20$ \\
$\mathrm{H}_{3} \mathrm{BO}_{3}$ & $30-40$ \\
Surfactant (SDS) & 0.4 \\
Graphene & 0.2
\end{tabular}

The size of sample mainly used for coating is $20 \times 10 \times 2$ $\mathrm{mm}$; this size was used for various testing of electrochemical and mechanical properties of composite coatings. The bath composition is shown in the Table 2, the parameters and conditions for electrodeposition were as; current density was 5 A dm ${ }^{-2}, 0.2 \mathrm{~g} \mathrm{~L}^{-1}$ graphene concentration in the conventional Watts bath solution, $\mathrm{pH}$ value was adjusted to $3-4$, one hour ultrasonication for better dispersion of graphene nanosheets, stirring speed was $400 \mathrm{rpm}$ and deposition time was one hour. The properties of composite coatings were characterized at different deposition temperatures $\left(15^{\circ} \mathrm{C}, 30^{\circ} \mathrm{C}, 45^{\circ} \mathrm{C}\right.$ and $60^{\circ} \mathrm{C}$, respectively).

Prior to electrodeposition, the samples were prepared by grinding with different grades of emery papers (240\#, 320\#, $600 \#$ and $1200 \#$, respectively) to obtain smooth, bright and uniform surfaces, then cleaning with different chemicals $(10 \%$ HCL and $5 \% \mathrm{H}_{2} \mathrm{SO}_{4}$ ) was performed to remove the surface impurities, dust, oil and oxides layer. The experimental setup contains two anode plates of nickel in size $70 \mathrm{~mm} \times 40 \mathrm{~mm} \times 1$ $\mathrm{mm}$ placed in the both ends of bath solution, carbon steel as a cathode adjusted between both anode plates. Surfactant sodium dodecyl sulfate (SDS) was used for reasonably good dispersion of graphene sheets owing to the SDS adsorption on the graphene sheets, which cause the electrostatic repletion between graphene layers.

\subsection{Characterization techniques}

The coatings were washed with deionized water and dried. The micro hardness of composite coatings was determined by using HXS-1000A micro hardness tester. A load of $200 \mathrm{~g}$ for $12 \mathrm{~s}$ was applied. Five different position of uniform distribution for each sample were tested and average hardness was obtained. Hitachi S-4700 scanning electron microscope was used for observation of coatings surface morphologies and EDAX spectrometer was used for composition analysis of deposited coatings. Thickness of the coating was measured by TT230 coating thickness gauge. The structural analysis and grain sizes of coatings were determined by using the Japanese D/max2500 X-ray diffractometer. For this characterization, test conditions for $\mathrm{Cu} \mathrm{K} \alpha$ radiation tube, voltage $40 \mathrm{kV}$, tube current $200 \mathrm{~mA}$, sampling width 0.02 , scanning width $20-90^{\circ}$ and scanning speed were $10^{\circ} \mathrm{min}^{-1}$. The surface roughness of the composite coating was measured using a Bruker Multimode atomic force microscopy (AFM).

The electrochemical tests were performed by using electrochemical workstation model CS350 (Corrtest, Beijing, China), and traditional setup of three electrodes cell. The saturated calomel electrode (SCE) was as reference electrode, platinum (Pt) as auxiliary electrode, composite film on carbon steel was encapsulated and exposed area of about $1 \mathrm{~cm}^{2}$ as a working electrode. The polarization curves of coatings were performed in $3.5 \% \mathrm{NaCl}$ solution. The scanning starts potential $0.3 \mathrm{mV}$ (relative to the open circuit potential), $0.5 \mathrm{~V}$ (set to end potential), and scanning rate is $1 \mathrm{mV} \mathrm{s}^{-1}$. Electrochemical impedance spectroscopy (EIS) of composite coating was performed. The deposited samples were immersed in $3.5 \% \mathrm{NaCl}$ solution to stabilize the open-circuit potential and the test frequency range of $0.01 \mathrm{~Hz}$ to $100 \mathrm{kHz}$ with $10 \mathrm{mV} \mathrm{AC}$ potential signal varied from open potential.

\section{Results and discussion}

\subsection{Characterization of graphene}

The SEM images of graphene sheets are shown in Fig. 1, the Xray diffraction patterns of graphene oxide (GO) and reduced graphene (rGO) are shown in Fig. 2. Characteristics of carbon peak (001) for GO sheets observed at $10^{\circ}$ corresponding to $d$ spacing or inter layer distance of $0.8 \mathrm{~nm}$ similar reported by Marcano and coworker. ${ }^{46}$ After reduction, (001) disappeared and the new peak (002) was observed at $2 \theta=25.4^{\circ}$ corresponding to the $d$-spacing of about $0.4 \mathrm{~nm}$ consistent with the

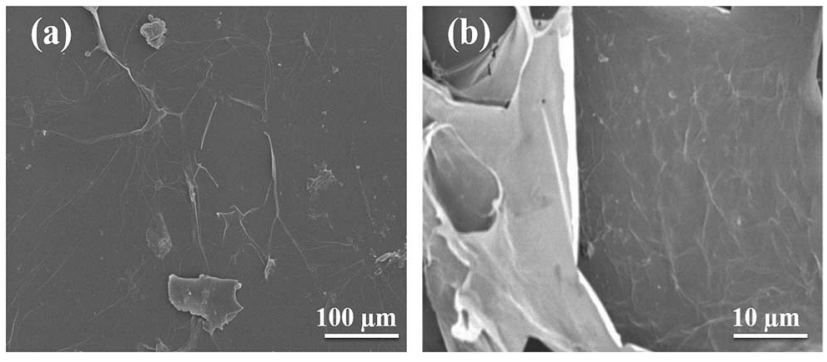

Fig. 1 SEM micrographs of graphene oxide sheets.

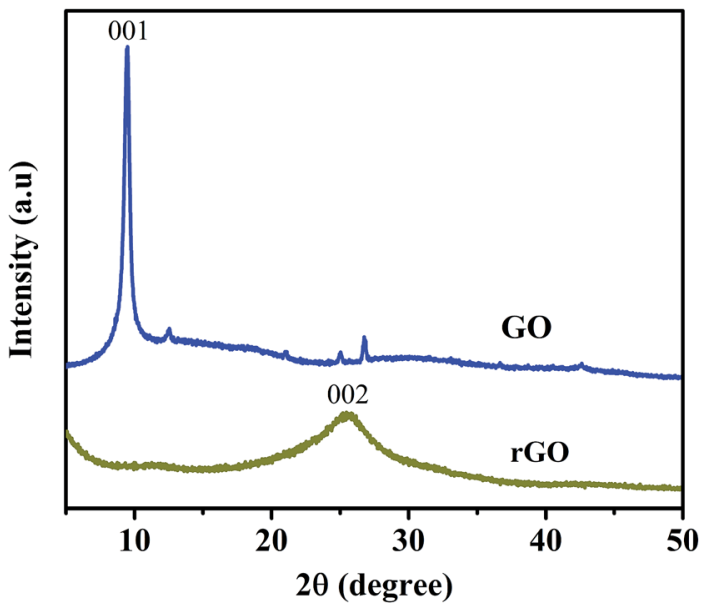

Fig. 2 XRD pattern of as synthesized graphene oxide and reduced graphene. 


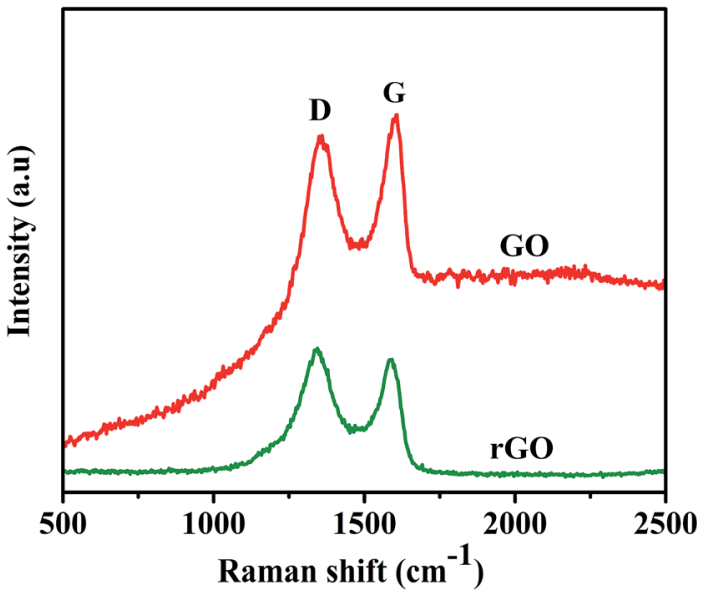

Fig. 3 Raman spectra of graphene oxide and reduced graphene used for electrochemical codeposition process.

reported ${ }^{48}$ which is in good arrangement of interlayer distance of graphene. To confirm the remarkable structural changes in the chemical reduction from GO to reduced graphene oxide are given in the Fig. 3. The Raman spectra of graphene shows the appearance of D peaks at $\sim 1350 \mathrm{~cm}^{-1}$ and G peaks at $\sim 1590$ $\mathrm{cm}^{-1}$ ensure the confirmation of lattice distortions. ${ }^{47}$ The ratios of $I_{\mathrm{D}} / I_{\mathrm{G}}$ peak intensity are about 0.8 and 0.9 for graphene oxide and reduced graphene oxide, respectively, showing the reduction in average size of $\mathrm{sp}^{2}$ domains and edge defects owing to the reduction of some $\mathrm{C}=\mathrm{C}$ bonds in graphene oxide. ${ }^{49}$

\subsection{Effect of deposition temperature on the surface morphology and carbon content in composite coatings}

The prepared composite coatings for this study possess good adhesion and stability to the substrate. Fig. 4 shows the surface morphologies of coatings deposited at different temperatures $15^{\circ} \mathrm{C}, 30^{\circ} \mathrm{C}, 45^{\circ} \mathrm{C}$ and $60^{\circ} \mathrm{C}$, respectively, from the bath containing $0.2 \mathrm{~g} \mathrm{~L}^{-1}$ graphene sheets. It is undoubtedly understanding that the deposition temperature has significant effect on the surface morphologies of nickel graphene composite coatings. The composite coatings become coarser, compact and the spherical morphologies was obtained when the deposition temperature increased from $15{ }^{\circ} \mathrm{C}$ to $45{ }^{\circ} \mathrm{C}$ (as shown in Fig. 4(a)-(c)). Further increases the deposition temperature, compactness of obtained coatings declined and degradation started. The reason may have expected that when the deposition temperature increased to $60{ }^{\circ} \mathrm{C}$, some voids and cracks appeared on the surface of the deposited coatings.

Fig. 4 reveals that the coarseness of composite coatings increased as the deposition temperature increase to peak value $45{ }^{\circ} \mathrm{C}$ and with further increase of temperature to $60{ }^{\circ} \mathrm{C}$, the surface roughness was not increased. The SEM micrographs shows the increasing trend in uniformly distribution of graphene sheets and the substrate was well deposited and fully covered with coatings without any surface cracks when the deposition temperature increases to $45^{\circ} \mathrm{C}$. The other reason is expected that the shape of grains growth and phase structure,
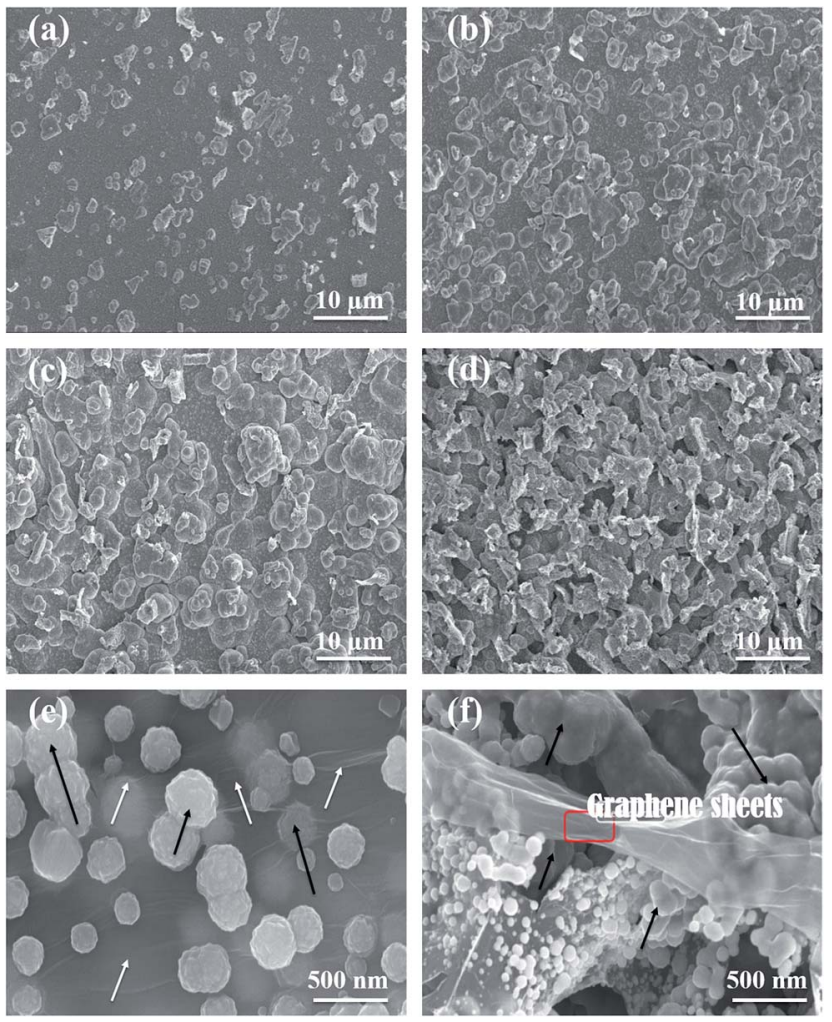

Fig. 4 SEM images: (a-d) for the surface morphologies of Ni-graphene composite coatings prepared at deposition temperatures $\left(15^{\circ} \mathrm{C}, 30^{\circ} \mathrm{C}, 45^{\circ} \mathrm{C}\right.$ and $60^{\circ} \mathrm{C}$, respectively). (e) Composite coating with white arrows shows the graphene layers and black arrows indicates the bulges shapes formation of $\mathrm{Ni}$-graphene composite. (f) The selected area represent the graphene sheets layers incorporated in the nickel matrix of composite coating and arrows express the graphene rich bulges morphology in composite coating.

actually, the coatings comprised of two types of spherical and flake like structures, which were increased as deposition temperature increases to peak value $45^{\circ} \mathrm{C}$, but at higher deposition temperature the coatings shows flake structure. In the Fig. 4(e-f) shows the bulges morphologies and incorporations of graphene layers into nickel matrix of composite coatings shown, white arrows show the graphene layers and black arrows indicate the bulges shapes formation of Ni-graphene composite in (Fig. 4e). Where in the (Fig. 4f) image, selected area represent the graphene sheets layers incorporated into the nickel matrix

Table 3 Surface roughness of composite coating deposited at different bath temperatures

\begin{tabular}{lll}
\hline & Roughness \\
\cline { 2 - 3 } $\begin{array}{ll}\text { Deposition temperature } \\
\left({ }^{\circ} \mathrm{C}\right)\end{array}$ & $\begin{array}{l}\text { Average roughness } \\
\left(R_{\mathrm{a}}\right)(\mathrm{nm})\end{array}$ & $\begin{array}{l}\text { Root mean square } \\
\text { roughness }\left(R_{\mathrm{q}}\right)(\mathrm{nm})\end{array}$ \\
\hline 15 & 34.2 & 47.7 \\
30 & 91.1 & 113 \\
45 & 128 & 199 \\
60 & 151 & 184
\end{tabular}



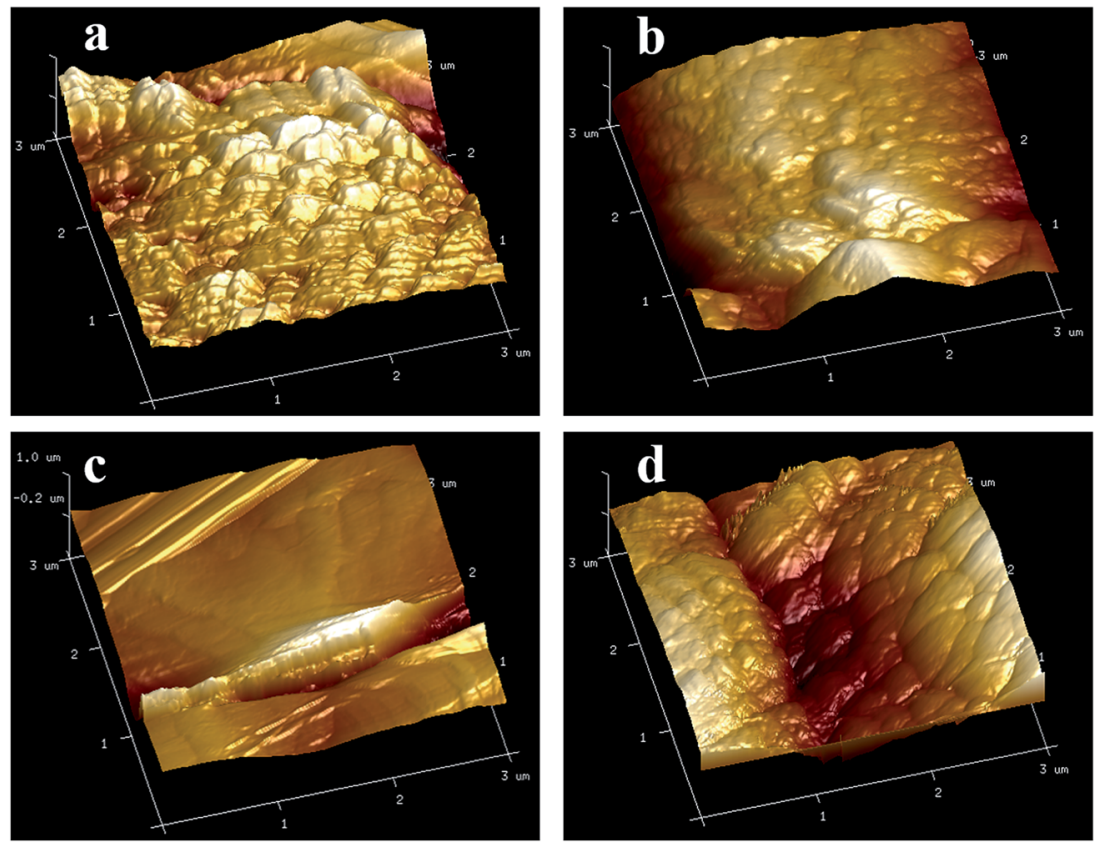

Fig. 5 AFM images (a-d) showing the surface roughness of $\mathrm{Ni}$-graphene composite coatings prepared at deposition temperatures $\left(15^{\circ} \mathrm{C}, 30^{\circ} \mathrm{C}\right.$, $45^{\circ} \mathrm{C}$ and $60^{\circ} \mathrm{C}$, respectively).
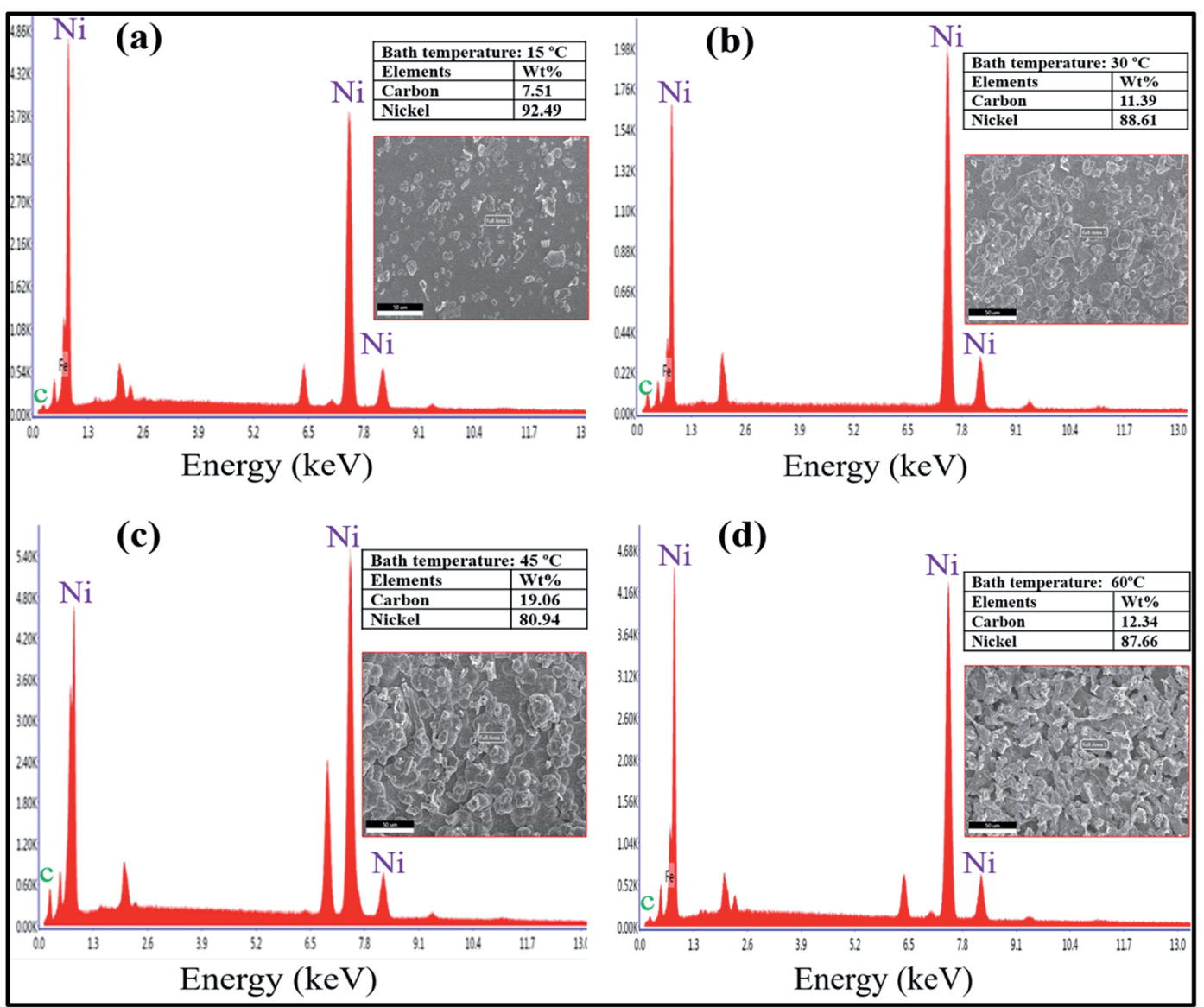

Fig. 6 EDS results show the effect of different bath temperatures on composition of coatings. 
and arrows express the graphene rich bulges morphology formation during the co deposition of nickel-graphene composite coating.

Surface roughness of the composite coating was measured by the atomic force microscopy (AFM) shown as in Table 3 and surface roughness morphologies are given in Fig. 5, which indicates that roughness of coating increases with increasing the deposition temperature and this remains almost same with further increasing of bath temperature after $45^{\circ} \mathrm{C}$. The reason is expected due to the not increasing of carbon content in the composite coating after peak deposition temperature of $45{ }^{\circ} \mathrm{C}$.

Energy dispersive spectroscopy (EDS) analysis was applied to confirm the presence of different elements in the prepared composite coatings. Fig. 6 shows EDS spectra and results of compositional analysis for Ni-graphene composite coatings obtained at different bath temperatures. The EDS results of coatings show the presence of $\mathrm{Ni}$ and $\mathrm{C}$ which ensure the incorporation of graphene in the nickel matrix during deposition process. The results of EDS illustrate the carbon contents incorporated in the composite coatings during electrodeposition at different temperatures, the carbon contents increases as the bath temperature increase to peak value $45^{\circ} \mathrm{C}$. It is expected that enough reduction of $\mathrm{Ni}$ ions which increases the possibility of captured graphene nanosheets into the nickel matrix because the graphene is more conductive and nickel ions likely to adsorbed on the graphene nanosheets result in forming the carbon content enriched bulges on the surface of composite coatings. On the other hand, carbon contents were decreased at high temperature $60{ }^{\circ} \mathrm{C}$. The reason is may be the rapidly moving nickel ions dissolved from the anode bar and there is not enough time for nickel ions to adsorb at graphene nanosheets, and agglomeration effect of graphene also dominated at high temperature which caused lower carbon contents incorporation in the composite coatings.

SEM was used to observe the cross section of coating; cross sectional photographs are shown in Fig. 7. Thickness was measured to study the effect of electrochemical deposition temperature on the thickness of $\mathrm{Ni}$-graphene composite coating. Fig. 8 shows the influence of bath temperature on the
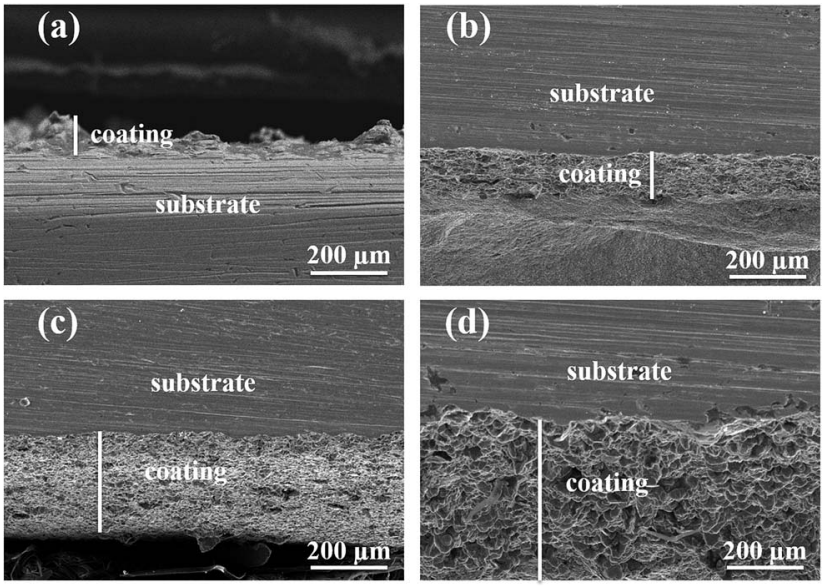

Fig. 7 Cross sectional photographs of the composite coating deposited at different deposition temperatures ((a) $15^{\circ} \mathrm{C}$, (b) $30^{\circ} \mathrm{C}$, (c) $45^{\circ} \mathrm{C}$ and (d) $60^{\circ} \mathrm{C}$ ).

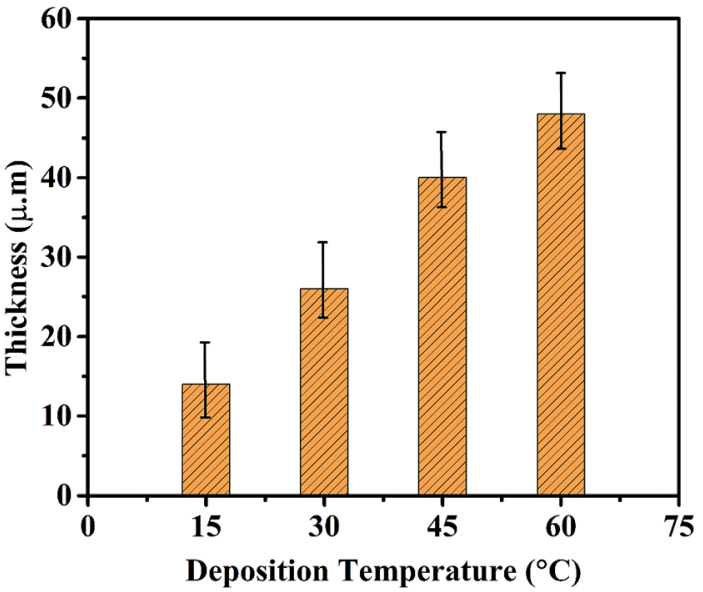

Fig. 8 Effect of bath temperature on the thickness of composite coating.

thickness of composite coating. It was found that the thickness was increased with the increases of deposition temperature.

\subsection{Grain sizes and micro hardness of deposited coatings}

Fig. 9 shows the XRD patterns of graphene based composite coatings deposited at temperatures $\left(15{ }^{\circ} \mathrm{C}, 30{ }^{\circ} \mathrm{C}, 45{ }^{\circ} \mathrm{C}\right.$ and $60{ }^{\circ} \mathrm{C}$, respectively). It clearly can be observed that the peak widths of deposited coatings at peak temperature $45{ }^{\circ} \mathrm{C}$ are more boarder than the peaks widths at lower or higher temperature. In general, the introduction of graphene nanosheets increases the preferred orientation at (200) with increasing the deposition temperature due to the increasing of graphene/carbon content in coating, which increases the peak intensity of (200). Nevertheless, the peak intensity of coating deposited at temperature of $60{ }^{\circ} \mathrm{C}$ was increased due to the rapid reduction of nickel ions at high temperature deposition and increasing the nucleation orientations on both (111) and (200) planes. Although, the nucleation preferably to take place around the graphene sheets and it is estimated that not all grains in the composite are affected by graphene sheets during high temperature deposition. This can be one reason of higher peak intensity of (200) than (111). These results suggest that the introduction of graphene nanosheets in Ni deposition greatly alter the pattern of preferred orientations, crystal orientation and growth behavior as also reported in other data. ${ }^{\mathbf{5 0}}$

This was attributed to decrease in the grain size of nickel matrix due to incorporating the graphene into nickel matrix and blocking the Ni crystal growth. The average grain sizes of the composite coatings prepared at different temperature were calculated by the Scherrer's equation ${ }^{35}$ and Scherrer's equation parameters are given in Table S1 of ESI. $\dagger$

$$
D=K \lambda / \beta \cos \theta
$$

where $D$ is the average crystalline size, $K$ is the Scherrer constant, $\lambda$ is the wave length, $\beta$ is the full width half maxima (FWHM) and $\theta$ is the diffraction angle.

The grain sizes of the deposited coatings at different bath temperatures are shown in the Fig. 10. The presence of 

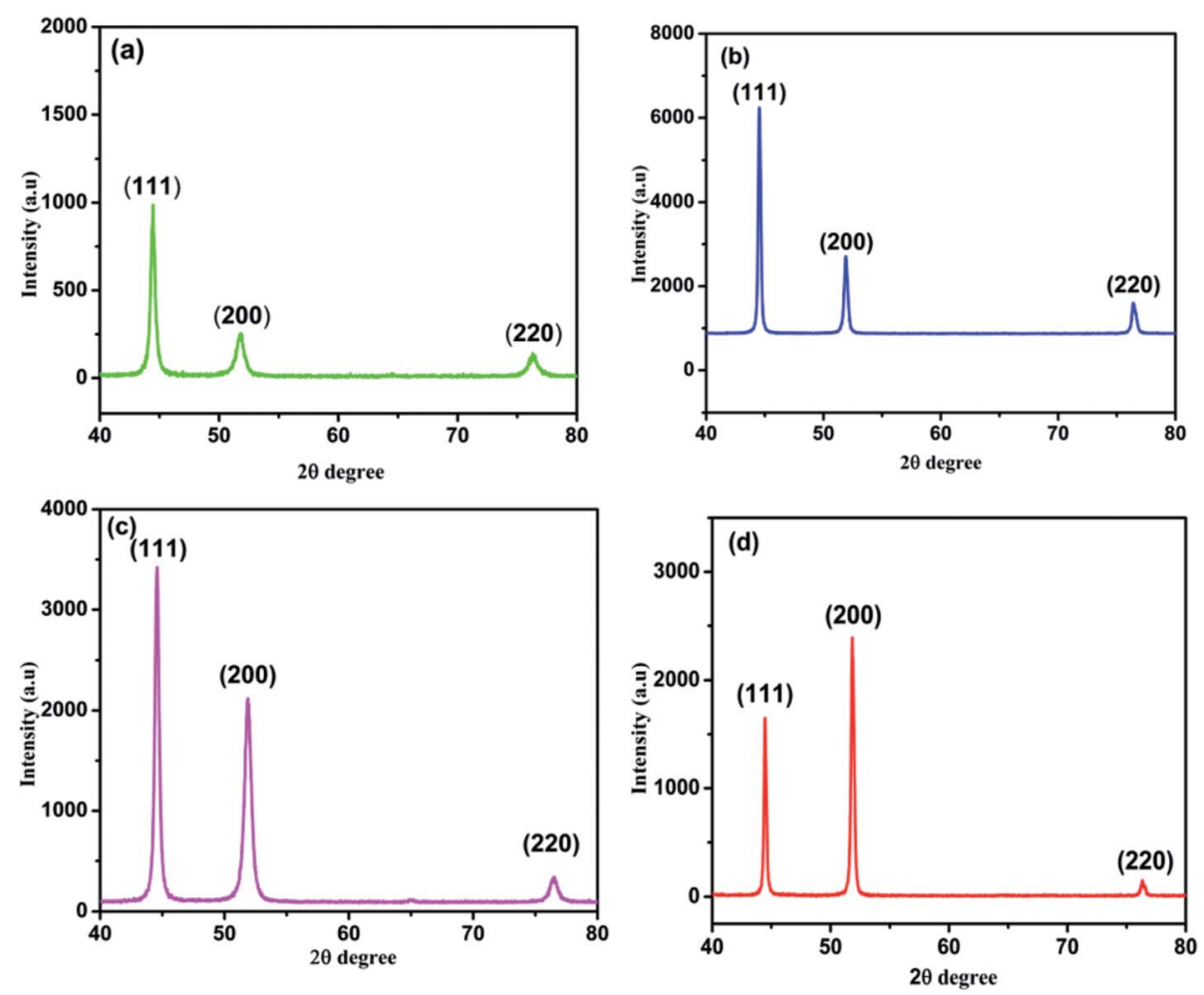

Fig. 9 XRD patterns of $\mathrm{Ni}$-graphene composite coatings deposited at temperatures (a) $15^{\circ} \mathrm{C}$, (b) $30^{\circ} \mathrm{C}$, (c) $45^{\circ} \mathrm{C}$ and (d) $60{ }^{\circ} \mathrm{C}$.

graphene into the nickel matrix ensured the grains refinement, ${ }^{27}$ because the graphene incorporated in nickel matrix hinder the grain growth for reduced nickel ions and also increased the nucleation sites. The grain sizes of the composite coatings were decreased as the deposition temperature increased up to the peak value temperature $45{ }^{\circ} \mathrm{C}$ then increased with further increasing the bath temperature. There are two possible reasons; firstly, at the lower temperature the nucleation process is slow that provided less nickel nucleation sites for graphene to incorporate into Ni matrix. Secondly, at the higher temperature the nickel reduction reaction is very fast, so

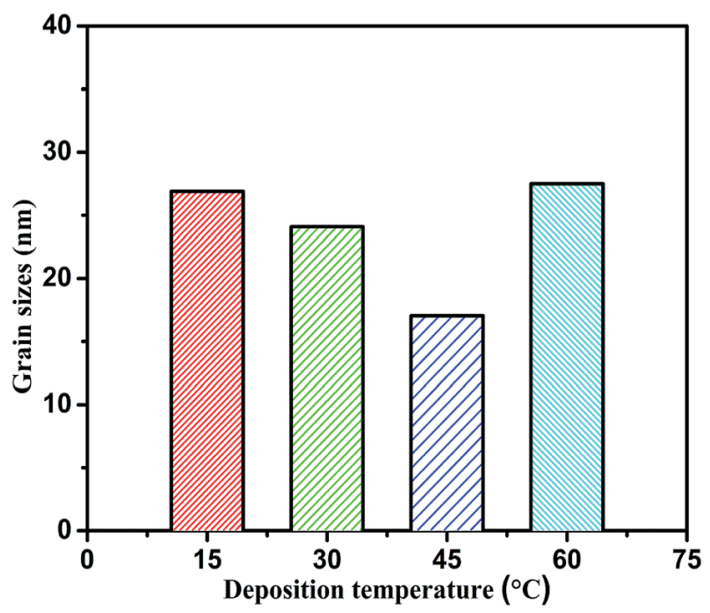

Fig. 10 Effect of deposition temperature on the grain sizes of composite coatings. less aggregate of graphene nanosheets engulfed into nickel matrix and also agglomeration of graphene occurred at higher temperature as discussed earlier. The above results show that the grain sizes was decreased due to the maximum incorporation of carbon contents in the coatings under optimum deposition temperature. It is suggested to study the optimum temperature which allows the large carbon contents addition in the composite coatings. The bath temperature $45{ }^{\circ} \mathrm{C}$ was observed as the peak value of deposition temperature at which

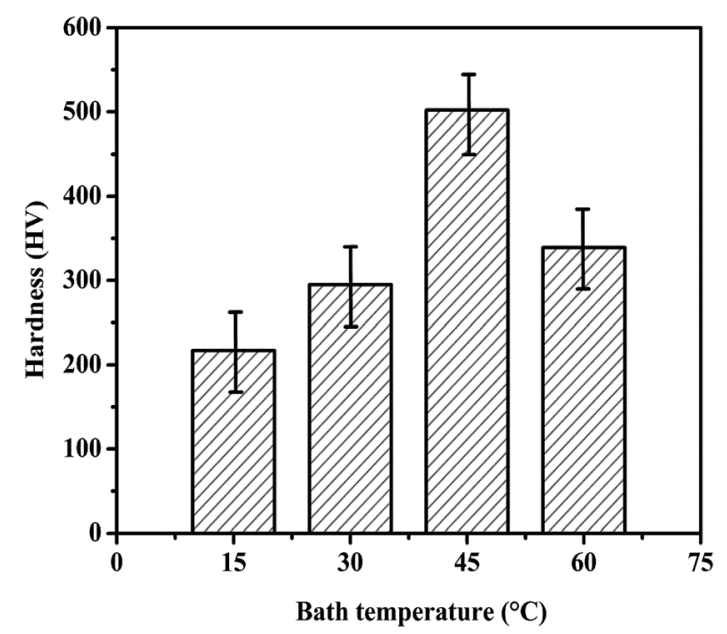

Fig. 11 Micro hardness of composite coatings prepared at different temperatures. 


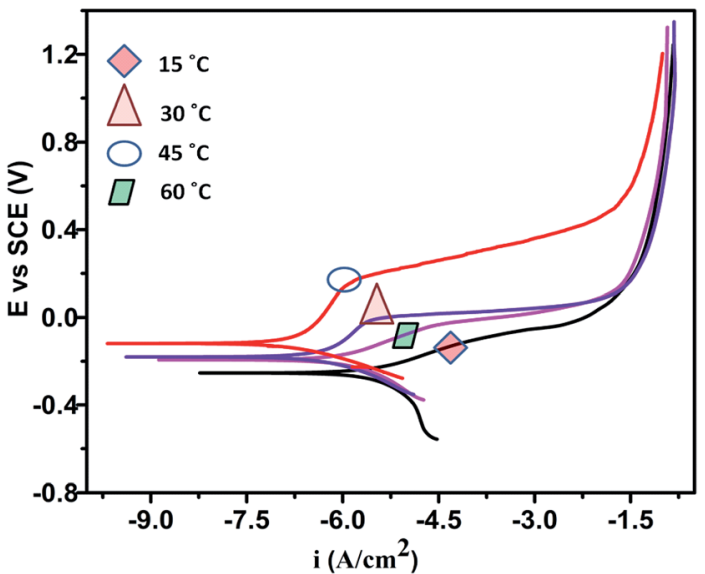

Fig. 12 Effect of deposition temperature on the polarization curves of composite coatings in $3.5 \% \mathrm{NaCl}$ solution.

maximum graphene concentration was incorporated in the coatings.

Fig. 11 demonstrates the effect of bath temperature on the Vickers Micro hardness of composite coatings. The hardness of nickel graphene composite coatings increased linearly up to the peak value of temperature $45{ }^{\circ} \mathrm{C}$. The micro hardness of the composite coatings changes in the similar drift as the carbon content does with the electrodeposition temperature. The presence of graphene nanosheets in the metal matrix resist the motion of dislocations and obstruct the plastic flow. ${ }^{27}$ In addition, the smaller size of graphene sheets that is particulate phase and intrinsic excellent mechanical properties of graphene are the others reasons of higher micro hardness. ${ }^{35}$ This increased in hardness is due the strengthening effects of smaller size graphene nanosheets existed in composite coatings.

\subsection{Effect of deposition temperature on corrosion resistance properties of deposited coatings}

The polarization curves of the Ni-graphene composite coatings deposited at different bath temperatures were performed and are shown in the Fig. 12. Table 4 contains the data of corrosion current densities $\left(I_{\text {corr }}\right)$ and corrosion potentials $\left(E_{\mathrm{v}}\right)$ determined from the polarization curves. It is clear from results that the composite coatings obtained at $45{ }^{\circ} \mathrm{C}$ have lower corrosion current densities and higher corrosion potentials than coatings obtained at lower and higher temperature, indicative of improved corrosion resistance of coatings deposited at $45{ }^{\circ} \mathrm{C}$. The composite coatings show the increasing corrosion resistance as the temperature increased from $15{ }^{\circ} \mathrm{C}$ to $45{ }^{\circ} \mathrm{C}$ (as shown in Table 3). With further increasing the deposition temperature, the corrosion resistance decreased significantly.

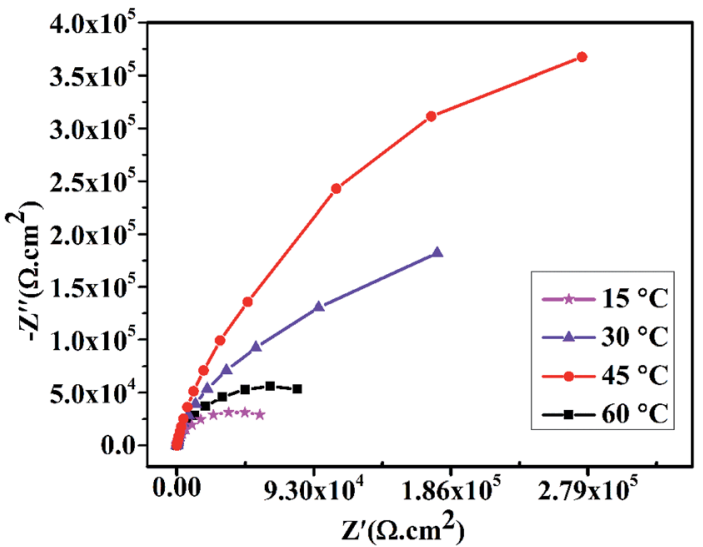

Fig. 13 Effect of deposition temperature on the impedance spectra of composite coatings in $3.5 \% \mathrm{NaCl}$ solution.

There are several factors responsible for improved and decreased corrosion resistance at different deposition temperatures. Firstly, the uniformly distributed graphene sheets filled the micron holes, crevices and gaps in the nickel matrix, homogeneous dispersion of graphene during the deposition process and inert physical barrier property of graphene are responsible for improved corrosion resistance. Secondly, when the deposition temperature rises to $60{ }^{\circ} \mathrm{C}$, fine cracks appeared on the surface of coatings and some hydrogen atoms absorbed on the coatings surface and diffused inside the deposited coatings and in result residual stress appeared, ${ }^{42,43}$ so decreased in corrosion resistance of composite coatings prepared at higher temperature $60^{\circ} \mathrm{C}$.

The electrochemical impedance spectroscopy (EIS) test was performed in $3.5 \% \mathrm{NaCl}$ solution to study the anti-corrosion properties of composite coatings obtained at different bath temperatures. Fig. 13 shows the Nyquist plots of composite coatings prepared at temperatures $\left(15{ }^{\circ} \mathrm{C}, 30{ }^{\circ} \mathrm{C}, 45{ }^{\circ} \mathrm{C}\right.$ and $60{ }^{\circ} \mathrm{C}$, respectively). In addition, the comparison of pure $\mathrm{Ni}$ coating and pure graphene coating deposited with similar method at $45{ }^{\circ} \mathrm{C}$ are shown in Fig. S1 of ESI. $\dagger$ It was found that the pure $\mathrm{Ni}$ and pure graphene coatings exhibit poor corrosion resistance property than $\mathrm{Ni}$-graphene composite coating. To test the long time performance of composite coating, EIS was performed to study the anti-corrosion property of composite coating prepared via similar method at $45{ }^{\circ} \mathrm{C}$ and impedance results are given in Fig. S2 of ESI. $\dagger$ It can be clearly observed that the coatings deposited at peak temperature $45{ }^{\circ} \mathrm{C}$ have higher impedance than coatings deposited at lower or higher temperatures. Meanwhile, the obtained EIS spectra of coatings deposited at lower or higher temperature shows narrow semi circles. In fact, the diameter of the semicircles decides the anticorrosion property of coatings and the larger diameter ensures

Table 4 Effect of deposition temperature on the corrosion potentials and corrosion current densities of composite coatings

\begin{tabular}{lllll}
\hline Deposition temperature $\left({ }^{\circ} \mathrm{C}\right)$ & 15 & 30 & 45 & 60 \\
$I_{\text {corr }}\left(\mathrm{A} \mathrm{cm}^{-2}\right)$ & $3.870 \times 10^{-6}$ & $1.474 \times 10^{-6}$ & $2.766 \times 10^{-7}$ \\
$E_{\text {corr }}(\mathrm{V})$ & -0.253 & -0.193 & -0.119
\end{tabular}


the better corrosion resistance. ${ }^{35}$ Therefore, it is obvious that the composite coating deposited at $45{ }^{\circ} \mathrm{C}$ acquires highest impedance and possess the superior anti corrosion property.

\section{Conclusions}

In this paper, $\mathrm{Ni}$-graphene composite coatings were successfully electrodeposited at temperatures $\left(15{ }^{\circ} \mathrm{C}, 30^{\circ} \mathrm{C}, 45^{\circ} \mathrm{C}\right.$ and $60{ }^{\circ} \mathrm{C}$, respectively). The surface morphologies, thickness and composition of composite coatings are greatly affected by electrodeposition temperature. The surface coarseness and carbon content in the composite coating increases with the deposition temperature until a peak value at temperature $45^{\circ} \mathrm{C}$, then the carbon content decreases with the further increasing of deposition temperature and surface roughness remain almost the same. The thickness of the Ni-graphene composite coatings were increased with the increasing of electrodeposition temperature. The results of XRD pattern reveal that the incorporation of graphene sheets in the nickel matrix increased the preferred orientation on (200) with the function of refining grain sizes. The grain sizes, micro hardness and corrosion resistance of the composite coatings change with the deposition temperature in the same way as carbon content performs, and these factors obtained the peak values at the optimum temperature $45^{\circ} \mathrm{C}$. These results demonstrate that the presence of graphene sheets in the composite coatings increase the surface roughness, improve the micro hardness, refine the grain sizes and enhance the corrosion resistance properties of composite coatings.

\section{Acknowledgements}

Ghulam Yasin is thanked for equal contribution as performed by the first author. Author also acknowledged and thanks to staff and teachers of the characterization center of Beijing University of Chemical technology, China and University of Engineering and Technology of Lahore, Pakistan for the useful contribution and help for this work.

\section{References}

$1 \mathrm{~J}$. Musil, Hard and superhard nanocomposite coatings, Surf. Coat. Technol., 2000, 125, 322-330.

2 P. Holubar, M. Jilek and M. Sima, Present and possible future applications of superhard nanocomposite coatings, Surf. Coat. Technol., 2000, 133-134, 145-151.

3 R. A. Andrievski, Films as nanostructured materials with characteristic mechanical properties, Mater. Trans., 2001, 42, 1471-1473.

4 S. Veprek and S. Reiprich, A concept for the design of novel superhard coatings, Thin Solid Films, 1995, 268, 64-71.

5 S. Veprek and A. S. Argon, Mechanical properties of superhard nanocomposites, Surf. Coat. Technol., 2001, 146, 175-182.

6 V. Provenzano and R. Holtz, Nanocomposites for high temperature applications, Mater. Sci. Eng., A, 1995, 204, 125-134.
7 L. Maya, W. Allen, A. Glover and J. Mabon, Gold nanocomposites, J. Vac. Sci. Technol., B: Microelectron. Nanometer Struct.-Process., Meas., Phenom., 1995, 13, 361365.

8 P. Karvankova, M. Veprek-Heijman, O. Zindulka, A. Bergmaier and S. Veprek, Superhard nc-TiN/a-BN and nc-TiN/a-TiB x/a-BN coatings prepared by plasma CVD and PVD: a comparative study of their properties, Surf. Coat. Technol., 2003, 163, 149-156.

9 Q. Li, T. Lei and W. Chen, Microstructural characterization of WCp reinforced Ni-Cr-B-Si-C composite coatings, Surf. Coat. Technol., 1999, 114, 285-291.

$10 \mathrm{~J}$. Vreeling, V. Ocelik and J. T. M. De Hosson, Ti-6Al-4V strengthened by laser melt injection of WC $\mathrm{p}$ particles, Acta Mater., 2002, 50, 4913-4924.

11 P. Baghery, M. Farzam, A. Mousavi and M. Hosseini, Ni-TiO nanocomposite coating with high resistance to corrosion and wear, Surf. Coat. Technol., 2010, 204, 3804-3810.

12 I. Garcia, J. Fransaer and J.-P. Celis, Electrodeposition and sliding wear resistance of nickel composite coatings containing micron and submicron SiC particles, Surf. Coat. Technol., 2001, 148, 171-178.

13 F. Mazaleyrat and L. Varga, Ferromagnetic nanocomposites, J. Magn. Magn. Mater., 2000, 215, 253-259.

14 B. Cantor, C. Allen, R. Dunin-Burkowski, M. Green, J. Hutchinson, K. O'Reilly, et al., Applications of nanocomposites, Scr. Mater., 2001, 44, 2055-2059.

15 R. Andrievski and A. Glezer, Size effects in properties of nanomaterials, Scr. Mater., 2001, 44, 1621-1624.

16 J. Musil, P. Karvankova and J. Kasl, Hard and superhard ZrNi-N nanocomposite films, Surf. Coat. Technol., 2001, 139, 101-109.

17 O. Savadogo, Chemically and electrochemically deposited thin films for solar energy materials, Sol. Energy Mater. Sol. Cells, 1998, 52, 361-388.

18 Z. Zainal, A. Kassim, M. Z. Hussein and C. H. Ching, Effect of bath temperature on the electrodeposition of copper tin selenide films from aqueous solution, Mater. Lett., 2004, 58, 2199-2202.

19 S.-C. Wang and W.-C. J. Wei, Kinetics of electroplating process of nano-sized ceramic particle/Ni composite, Mater. Chem. Phys., 2003, 78, 574-580.

20 A. Góral, Nanoscale structural defects in electrodeposited Ni/ $\mathrm{Al}_{2} \mathrm{O}_{3}$ composite coatings, Surf. Coat. Technol., 2017, 319, 2332.

21 G. Maurin and A. Lavanant, Electrodeposition of nickel/ silicon carbide composite coatings on a rotating disc electrode, J. Appl. Electrochem., 1995, 25, 1113-1121.

22 Y. Zhou, F. Q. Xie, X. Q. Wu, W. D. Zhao and X. Chen, A novel plating apparatus for electrodeposition of $\mathrm{Ni}-\mathrm{SiC}$ composite coatings using circulating-solution co-deposition technique, J. Alloys Compd., 2017, 699, 366-377.

23 X. H. Chen, C. S. Chen, H. N. Xiao, H. B. Liu, L. P. Zhou, S. L. Li, et al., Dry friction and wear characteristics of nickel/carbon nanotube electroless composite deposits, Tribol. Int., 2006, 39, 22-28. 
24 L. Shi, C. F. Sun, P. Gao, F. Zhou and W. M. Liu, Electrodeposition and characterization of $\mathrm{Ni}-\mathrm{Co}-$ carbon nanotubes composite coatings, Surf. Coat. Technol., 2006, 200, 4870-4875.

25 X. H. Chen, C. S. Chen, H. N. Xiao, F. Q. Cheng, G. Zhang and G. J. Yi, Corrosion behavior of carbon nanotubes-Ni composite coating, Surf. Coat. Technol., 2005, 191, 351-356.

26 D. Prasai, J. C. Tuberquia, R. R. Harl, G. K. Jennings and K. I. Bolotin, Graphene: Corrosion-Inhibiting Coating, ACS Nano, 2012, 6, 1102-1108.

27 C. M. P. Kumar, T. V. Venkatesha and R. Shabadi, Preparation and corrosion behavior of $\mathrm{Ni}$ and $\mathrm{Ni}$-graphene composite coatings, Mater. Res. Bull., 2013, 48, 1477-1483.

28 H. Algul, M. Tokur, S. Ozcan, M. Uysal, T. Cetinkaya, H. Akbulut, et al., The effect of graphene content and sliding speed on the wear mechanism of nickel-graphene nanocomposites, Appl. Surf. Sci., 2015, 359, 340-348.

29 R. Berlia, M. P. Kumar and C. Srivastava, Electrochemical behavior of Sn-graphene composite coating, RSC Adv., 2015, 5, 71413-71418.

30 S. Chen, L. Brown, M. Levendorf, W. Cai, S.-Y. Ju, J. Edgeworth, et al., Oxidation Resistance of GrapheneCoated $\mathrm{Cu}$ and Cu/Ni Alloy, ACS Nano, 2011, 5, 1321-1327.

31 S. Mayavan, T. Siva and S. Sathiyanarayanan, Graphene ink as a corrosion inhibiting blanket for iron in an aggressive chloride environment, RSC Adv., 2013, 3, 24868-24871.

32 L. Kyhl, S. F. Nielsen, A. G. Cabo, A. Cassidy, J. A. Miwa and L. Hornekaer, Graphene as an anti-corrosion coating layer, Faraday Discuss., 2015, 180, 495-509.

33 C. Gómez-Navarro, M. Burghard and K. Kern, Elastic Properties of Chemically Derived Single Graphene Sheets, Nano Lett., 2008, 8, 2045-2049.

34 S.-K. Lee, H. Y. Jang, S. Jang, E. Choi, B. H. Hong, J. Lee, et al., All Graphene-Based Thin Film Transistors on Flexible Plastic Substrates, Nano Lett., 2012, 12, 3472-3476.

35 K. Jiang, J. Li and J. Liu, Electrochemical codeposition of graphene platelets and nickel for improved corrosion resistant properties, RSC Adv., 2014, 4, 36245-36252.

36 M. Rastei, S. Colis, R. Meckenstock, O. Ersen and J. Bucher, Pulsed electrodeposition and magnetism of twodimensional assembly of controlled-size Co particles on $\mathrm{Si}$ substrates, Surf. Sci., 2006, 600, 2178-2183.

37 S. Armyanov, Crystallographic structure and magnetic properties of electrodeposited cobalt and cobalt alloys, Electrochim. Acta, 2000, 45, 3323-3335.
38 P. Cavallotti, A. Vicenzo, M. Bestetti and S. Franz, Microelectrodeposition of cobalt and cobalt alloys for magnetic layers, Surf. Coat. Technol., 2003, 169, 76-80.

39 M. M. Abou-Krisha, Influence of $\mathrm{Ni}^{2+}$ concentration and deposition potential on the characterization of thin electrodeposited Zn-Ni-Co coatings, Mater. Chem. Phys., 2011, 125, 621-627.

40 M. Farzaneh, K. Raeissi and M. Golozar, Effect of current density on deposition process and properties of nanocrystalline Ni-Co-W alloy coatings, J. Alloys Compd., 2010, 489, 488-492.

41 M. H. Seo, D. J. Kim and J. S. Kim, The effects of pH and temperature on Ni-Fe-P alloy electrodeposition from a sulfamate bath and the material properties of the deposits, Thin Solid Films, 2005, 489, 122-129.

42 X. Qiao, H. Li, W. Zhao and D. Li, Effects of deposition temperature on electrodeposition of zinc-nickel alloy coatings, Electrochim. Acta, 2013, 89, 771-777.

43 C. Guo, Y. Zuo, X. Zhao, J. Zhao and J. Xiong, The effects of electrodeposition current density on properties of Ni-CNTs composite coatings, Surf. Coat. Technol., 2008, 202, 32463250 .

44 H. Y. Lee and S. G. Kim, Characteristics of Ni deposition in an alkaline bath for $\mathrm{Zn}-\mathrm{Ni}$ alloy deposition on steel plates, Surf. Coat. Technol., 2000, 135, 69-74.

45 M. M. Abou-Krisha, Electrochemical studies of zinc-nickel codeposition in sulphate bath, Appl. Surf. Sci., 2005, 252, 1035-1048.

46 D. C. Marcano, D. V. Kosynkin, J. M. Berlin, A. Sinitskii, Z. Sun, A. Slesarev, et al., Improved synthesis of graphene oxide, ACS Nano, 2010, 4, 4806-4814.

47 S. Stankovich, D. A. Dikin, R. D. Piner, K. A. Kohlhaas, A. Kleinhammes, Y. Jia, et al., Synthesis of graphene-based nanosheets via chemical reduction of exfoliated graphite oxide, Carbon, 2007, 45, 1558-1565.

48 I. K. Moon, J. Lee, R. S. Ruoff and H. Lee, Reduced graphene oxide by chemical graphitization, Nat. Commun., 2010, 1, 73.

49 Y. Xue, L. Zhu, H. Chen, J. Qu and L. Dai, Multiscale patterning of graphene oxide and reduced graphene oxide for flexible supercapacitors, Carbon, 2015, 92, 305-310.

50 P. Liu, K. L. White, H. Sugiyama, J. Xi, T. Higuchi, T. Hoshino, et al., Influence of trace amount of welldispersed carbon nanotubes on structural development and tensile properties of polypropylene, Macromolecules, 2013, 46, 463-473. 